\title{
Cytogenetic analyses of eight species in the genus Leptodactylus Fitzinger, 1843 (Amphibia, Anura, Leptodactylidae), including a new diploid number and a karyotype with multiple translocations
}

Thiago Gazoni ${ }^{{ }^{*}}$, Simone L Gruber ${ }^{1}$, Ana PZ Silva², Olivia GS Araújo ${ }^{3}$, Hideki Narimatsu', Christine Strüssmann ${ }^{4}$, Célio FB Haddad ${ }^{3}$ and Sanae Kasahara ${ }^{1}$

\begin{abstract}
Background: The karyotypes of Leptodactylus species usually consist of 22 bi-armed chromosomes, but morphological variations in some chromosomes and even differences in the $2 n$ have been reported. To better understand the mechanisms responsible for these differences, eight species were analysed using classical and molecular cytogenetic techniques, including replication banding with BrdU incorporation.
\end{abstract}

Results: Distinct chromosome numbers were found: $2 n=22$ in Leptodactylus chaquensis, L. labyrinthicus, $L$. pentadactylus, L. petersii, L. podicipinus, and L. rhodomystax; $2 n=20$ in Leptodactylus sp. (aff. podicipinus); and $2 n=24$ in L. marmoratus. Among the species with $2 n=22$, only three had the same basic karyotype. Leptodactylus pentadactylus presented multiple translocations, L. petersii displayed chromosome morphological discrepancy, and L. podicipinus had four pairs of telocentric chromosomes. Replication banding was crucial for characterising this variability and for explaining the reduced $2 \mathrm{n}$ in Leptodacty/us sp. (aff. podicipinus). Leptodacty/us marmoratus had few chromosomes with a similar banding patterns to the $2 n=22$ karyotypes. The majority of the species presented a single NOR-bearing pair, which was confirmed using Ag-impregnation and FISH with an rDNA probe. In general, the NOR-bearing chromosomes corresponded to chromosome 8, but NORs were found on chromosome 3 or 4 in some species. Leptodactylus marmoratus had NORs on chromosome pairs 6 and 8. The data from C-banding, fluorochrome staining, and FISH using the telomeric probe helped in characterising the repetitive sequences. Even though hybridisation did occur on the chromosome ends, telomere-like repetitive sequences outside of the telomere region were identified. Metaphase I cells from L. pentadactylus confirmed its complex karyotype constitution because 12 chromosomes appeared as ring-shaped chain in addition to five bivalents.

Conclusions: Species of Leptodacty/us exhibited both major and minor karyotypic differences which were identified by classical and molecular cytogenetic techniques. Replication banding, which is a unique procedure that has been used to obtain longitudinal multiple band patterns in amphibian chromosomes, allowed us to outline the general mechanisms responsible for these karyotype differences. The findings also suggested that L. marmoratus, which was formerly included in the genus Adenomera, may have undergone great chromosomal repatterning.

Keywords: FISH, Replication banding, BrdU, Fluorochrome staining, Ag-NOR, C-banding

\footnotetext{
*Correspondence: thiago_gazoni@hotmail.com

'Departamento de Biologia, Instituto de Biociências, Universidade Estadual

Paulista, UNESP, Rio Claro, São Paulo, Brazil

Full list of author information is available at the end of the article
} 


\section{Background}

The genus Leptodactylus currently consists of 89 species that are distributed from the southern United States to Argentina [1]. The majority of these species occurs in the Neotropical region, and 67 have been recorded in Brazil [2].

Major changes have been introduced in the family Leptodactylidae because of the extensive taxonomic and systematic reviews that have occurred in the last years [3-5]. For example, the number of genera was reduced from 57 to only four, with representatives of Adenomera Steindachner, 1867, Lithodytes Fitzinger, 1843, and Vanzolinius Heyer, 1974 allocated in the genus Leptodactylus. Recently, other modifications have been suggested for Leptodactylidae by Pyron and Wiens [6], who considered the family as composed of 13 genera and again recognised Adenomera and Lithodytes as valid genera, even though synapomorphies and/or individual diagnosis have not been pointed out. Furthermore, the relationship between Adenomera and Leptodactylus remains a controversial issue $[7,8]$.

Currently, approximately 40 species of Leptodactylus, sensu Frost et al. [3], have been karyotyped according to the revisions made by King [9], Kuramoto [10], AmaroGhilardi et al. [11], and Green and Sessions [12], complemented with subsequent information from Campos et al. [13] and Zaracho and Hernando [14]. The predominant diploid number is $2 n=22$ and the karyotype constitution is considered conservative, including bi-armed metacentric, submetacentric, and subtelocentric chromosomes, which results in a fundamental number of chromosome arms of FN $=44$. Nevertheless, a variable number of telocentric chromosomes has been reported in some karyotypes, which alters the FN. It is noteworthy that discrepant chromosome numbers, such as $2 \mathrm{n}=18,23,24$, and 26, are almost exclusively restricted to the former representatives of Adenomera and Lithodytes. The single known exception is Leptodactylus silvanimbus McCranie, Wilson and Porras, 1980, in which a diploid number of $2 \mathrm{n}=24$ was reported [11].

The first chromosome analyses on Leptodactylus were based exclusively on standard staining techniques. The first reports using differential staining did not appear until the 1990s, and it was not until many years later that molecular cytogenetic techniques were used [11,13-20]. However, studies using autoradiographic methods had been reported before $[21,22]$. Banding techniques have generated a larger number of markers that cytogenetically distinguish species or populations, but data on the chromosomal evolution of the genus Leptodactylus remain minimal.

This paper concerns the cytogenetic analyses of eight species of Leptodactylus, one of which has not yet been identified to species level. Taking into consideration that some of these species present distinct chromosome numbers or constitutions, both routine and molecular cytogenetic techniques were used. To better understand the mechanisms responsible for the karyotype variability observed within this genus, the present study emphasised the comparisons of the replication banding patterns using 5bromodeoxyuridine incorporation.

\section{Methods}

\section{Analysed species}

All individuals were collected in the wild under governmental collection permits issued by the Instituto Chico Mendes de Conservação da Biodiversidade (ICMBio) to TG, OGSA, HN, CS, and CFBH. The euthanasia was performed by deep anesthesia under consent and approval of the ethics committee in animal use - CEUA (permission 005/2009), Instituto de Biociências, UNESP, Rio Claro, SP, Brazil.

Cytogenetic analyses were performed on 34 specimens: three Leptodactylus chaquensis Cei, 1950; three Leptodactylus labyrinthicus (Spix, 1824); seven Leptodactylus marmoratus (Steindachner, 1867); one Leptodactylus pentadactylus (Laurenti, 1768); two Leptodactylus petersii (Steindachner, 1864); nine Leptodactylus podicipinus (Cope, 1862); three Leptodactylus rhodomystax Boulenger, 1884; and six Leptodactylus sp. (aff. podicipinus), collected in the Brazilian states of Amapá (AP), Mato Grosso (MT), Mato Grosso do Sul (MS), Minas Gerais (MG), and São Paulo (SP) (Additional file 1). Almost all the voucher animals were deposited in the amphibian collection Célio F. B. Haddad (CFBH) housed in the Departamento de Zoologia, Instituto de Biociências, UNESP, Rio Claro, SP, Brazil, except one specimen of L. labyrinthicus collected in São Joaquim da Barra (SP), that was identified with the field number RJS 1420.

\section{Standard and molecular cytogenetic techniques}

Direct chromosome preparations were obtained from bone marrow, liver, and testis and from intestinal epithelium $[23,24]$. For some animals, cell suspensions were obtained via lymphocyte cultures [25]. In vitro or in vivo treatments with 5-bromodeoxyuridine (BrdU) were used $[16,25]$ to differentiate replication bands. Standard staining was performed with Giemsa, and differential staining was performed using the techniques of Ag-NOR [26], Cbanding [27], Fluorochrome Plus Giemsa (FPG) [28], and DAPI and $\mathrm{CMA}_{3}$ fluorochrome staining [29]. The rDNA probe HM123 [30] was used in fluorescence in situ hybridisation (FISH) experiments [31] and a telomeric probe was used according to the manufacturer's manual (Dako Cytomation Denmark A/S Kit). The bi-armed chromosomes were classified as metacentric, submetacentric, or subtelocentric and the chromosomes that were uni-armed were classified as telocentric $[12,32]$. 


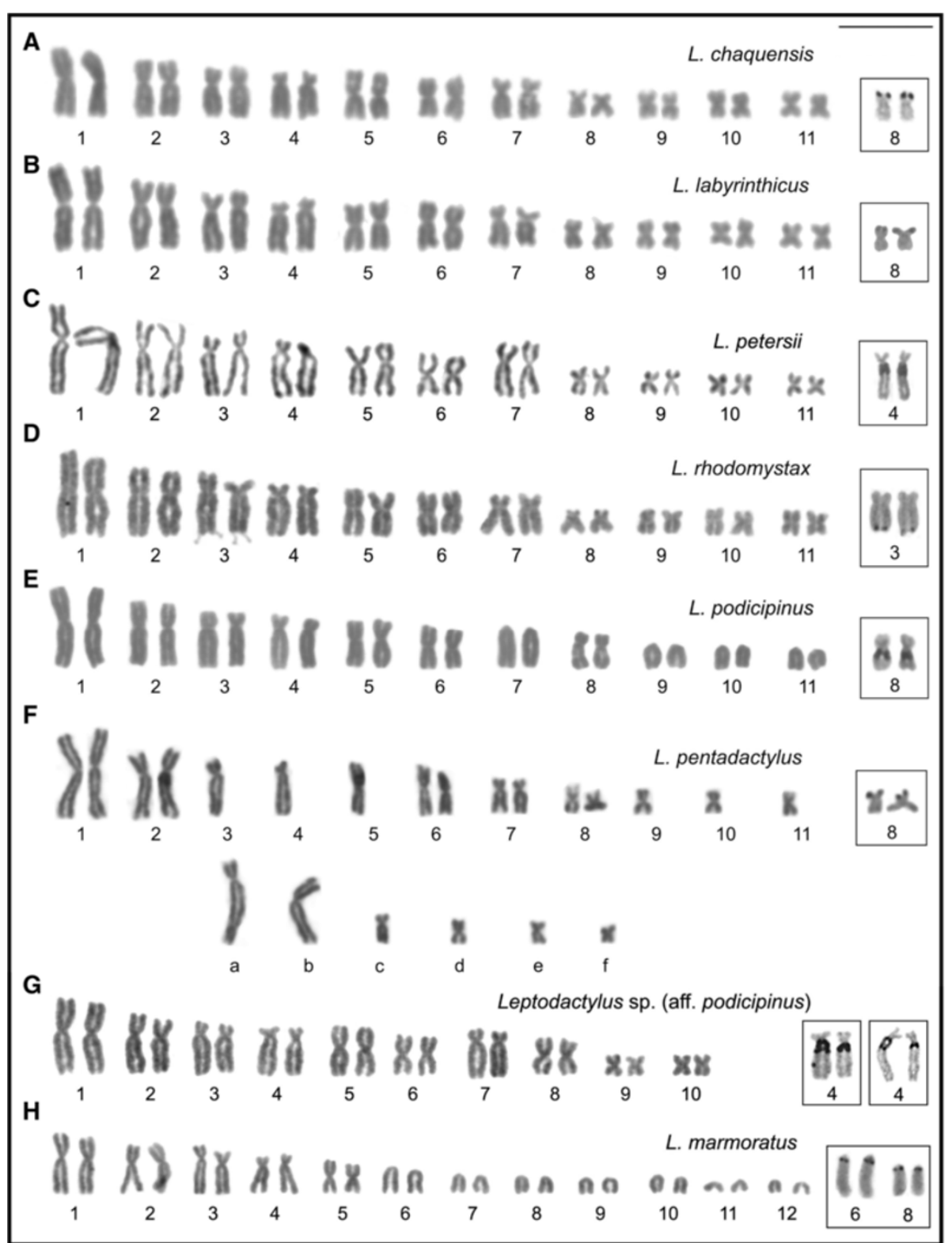

Figure 1 Giemsa-stained karyotypes and chromosome pairs with Ag-NOR of Leptodactylus. A. L. chaquensis, male, $2 \mathrm{n}=22 ; \mathbf{B}$. L. labyrinthicus, male, $2 n=22 ;$ C. L. petersii, male, $2 n=22 ; \mathbf{D}$. L. rhodomystax, juvenile, $2 n=22 ; \mathbf{E}$. L. podicipinus, female, $2 n=22 ; F$. $L$. pentadactylus, male, $2 n=22 ; \mathbf{G}$. Leptodactylus sp. (aff. podicipinus), male, $2 n=20 ; \mathbf{H}$. L. marmoratus, juvenile, $2 n=24$. In $\mathbf{F}$, the letters $\mathbf{a}, \mathbf{b}, \mathbf{c}, \mathbf{d}, \mathbf{e}$, and $\mathbf{f}$ correspond to the rearranged chromosomes. Insets show chromosome pairs with Ag-NOR. Bar $=10 \mu \mathrm{m}$.

\section{Results}

\section{Karyotype constitution and meiosis}

Leptodactylus chaquensis, L. labyrinthicus, L. petersii, and L. rhodomystax had $2 \mathrm{n}=22, \mathrm{FN}=44$, and karyotypes formed by seven large- and medium-sized pairs and four small pairs (Figure 1A-D). Among these, pairs 1, 5, 6, 9, 10 , and 11 were metacentric; pairs $2,3,7$, and 8 were submetacentric; and pair 4 was subtelocentric. Despite the submetacentric morphology, the chromosome 7 in L. petersii had greater relative length and distinct arm length ratio regarding those of the chromosome 7 of the remaining species. In the karyogram of L. petersii, chromosome 7 was the $5^{\text {th }}$ in size.

Leptodactylus podicipinus had $2 \mathrm{n}=22, \mathrm{FN}=36$, and a karyotype formed by seven large- and medium-sized pairs and four small pairs (Figure 1E). Among these, pairs 1, 5, and 6 were metacentric; pairs 2,3 , and 8 were submetacentric; pair 4 was subtelocentric; and pairs 7, 9, 10, and 11 were telocentric. Leptodactylus pentadactylus had $2 \mathrm{n}=22, \mathrm{FN}=44$, and an unusual karyotype (Figure $1 \mathrm{~F}$ ), in which only the chromosomes $1,2,6,7$, and 8 could be paired. Chromosomes 3, 4, 5, 9, 10, and 11, along with six 


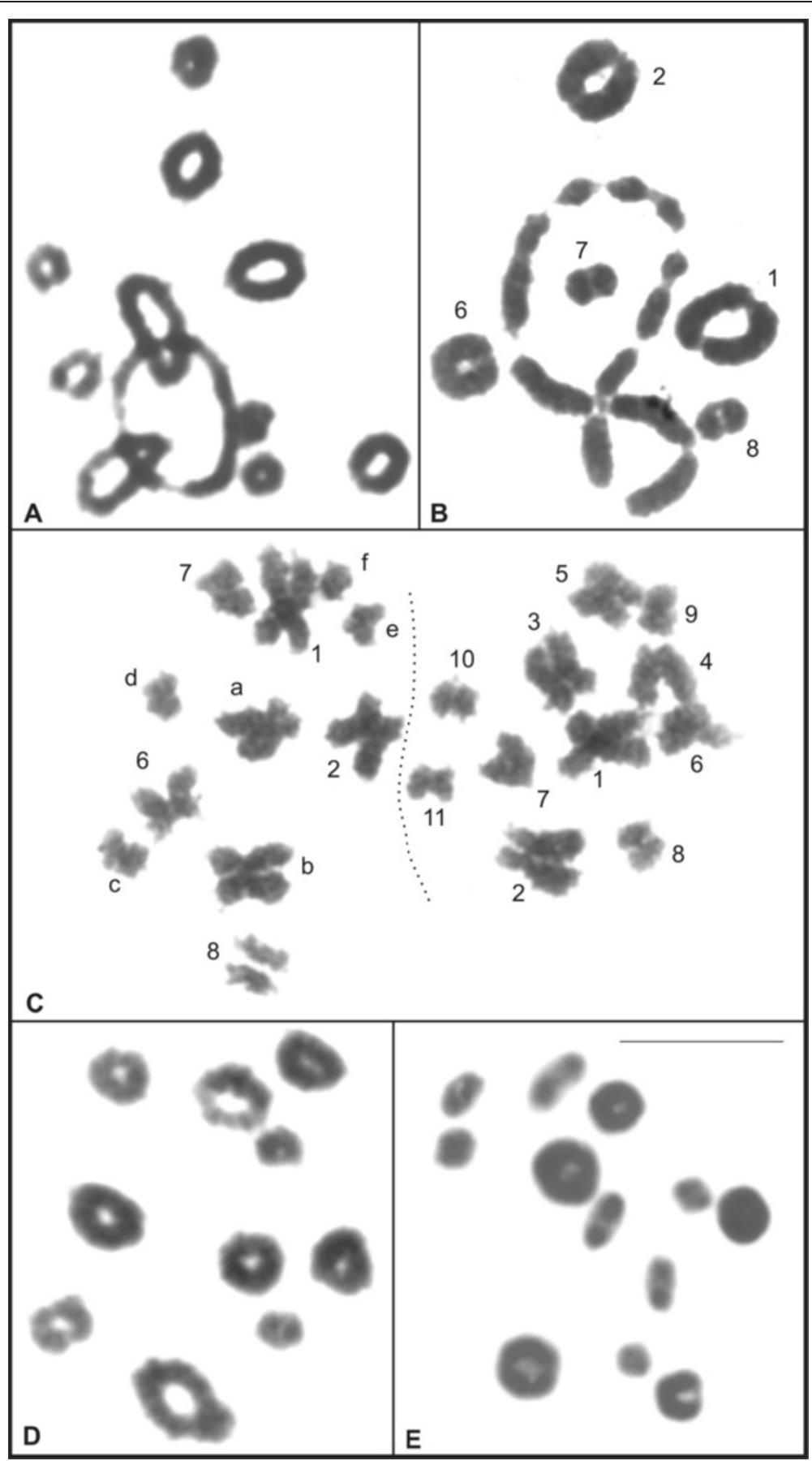

Figure 2 Giemsa-stained meiotic cells of Leptodactylus. A. metaphase I of L. podicipinus, with 11 bivalents; B. metaphase I of L. pentadactylus, with five bivalents and a ring-chain formed by 12 chromosomes; C. metaphases II of L. pentadactylus, showing 11 chromosomes, tentatively identified in each cell; $\mathbf{D}$. metaphase I of Leptodactylus sp. (aff. podicipinus), with 10 bivalents; E. metaphase I of L. marmoratus, with 12 bivalents. In $\mathbf{C}$, the letters $\mathbf{a}, \mathbf{b}, \mathbf{c}, \mathbf{d}, \mathbf{e}$, and $\mathbf{f}$ correspond to the rearranged chromosomes. Bar $=10 \mu \mathrm{m}$.

others designated as $\mathbf{a}, \mathbf{b}, \mathbf{c}, \mathbf{d}, \mathbf{e}$, and $\mathbf{f}$, were unpaired elements. With exception of elements a to $\mathbf{f}$, the L. pentadactylus chromosomes 1 to 11 were morphologically equivalent to chromosomes 1 to 11 observed in L. chaquensis, L. labyrinthicus, and L. rhodomystax. Chromosome a was subtelocentric; chromosomes $\mathbf{b}$ and $\mathbf{c}$ were submetacentric; and chromosomes $\mathbf{d}$, e, and $\mathbf{f}$ were metacentric. Leptodactylus sp. (aff. podicipinus) had $2 \mathrm{n}=20, \mathrm{FN}=40$, and a karyotype formed by eight large- and medium-sized pairs and two small pairs (Figure 1G). Among these, pairs 


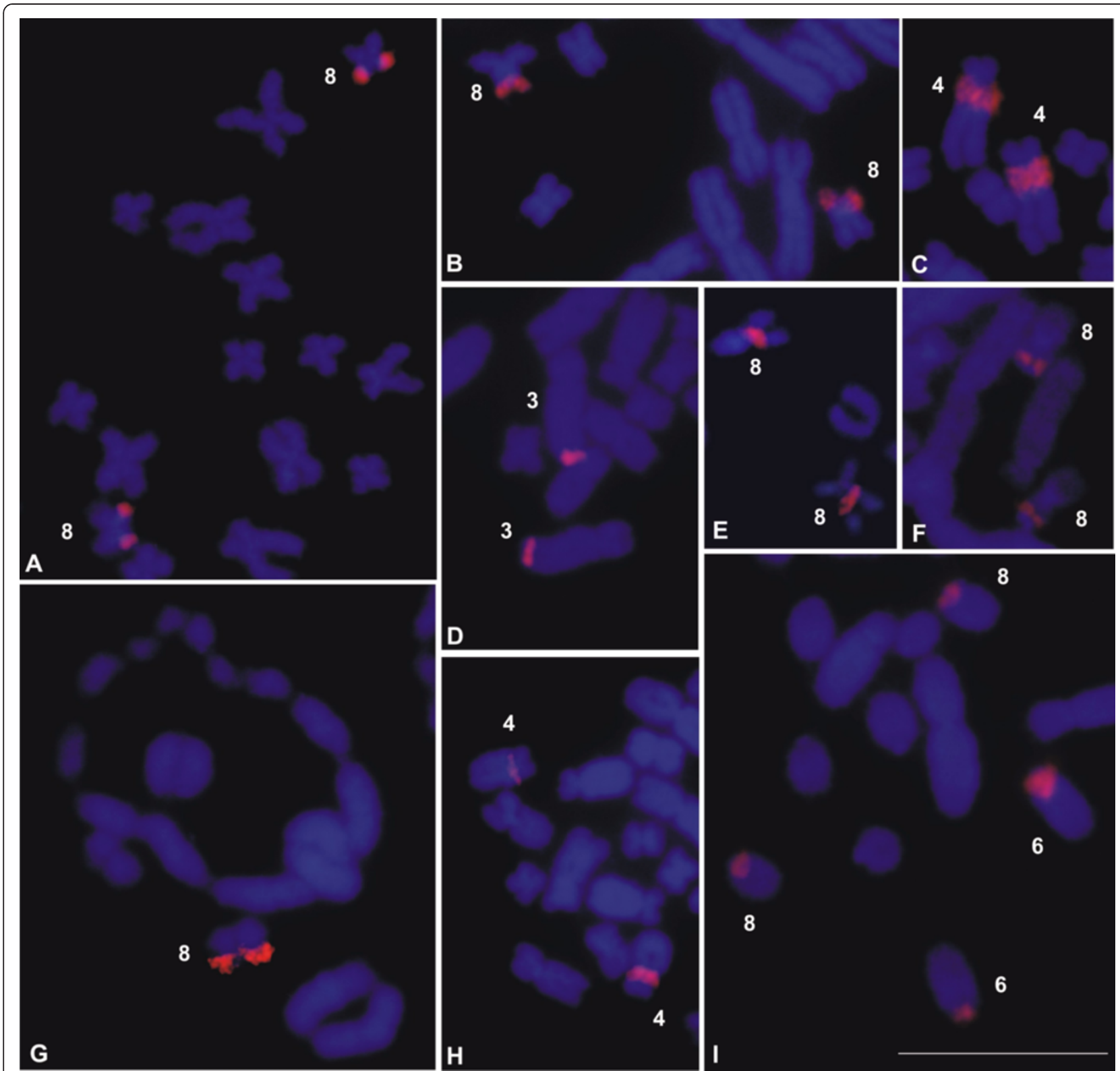

Figure 3 FISH using an rDNA probe in Leptodactylus. A. partial metaphase of L. chaquensis; B. partial metaphase of L. labyrinthicus; C. partial metaphase of L. petersii; D. partial metaphase of L. rhodomystax; E. partial metaphase of L. podicipinus; F. partial mitotic metaphase and $\mathbf{G}$. metaphase I cell of L. pentadactylus; H. partial metaphase of Leptodactylus sp. (aff. podicipinus); I. partial metaphase of L. marmoratus. Bar = 10 Hm.

$1,5,6,8,9$, and 10 were metacentric; pairs 2 and 3 were submetacentric; and pairs 4 and 7 were subtelocentric. In the karyogram of Leptodactylus sp. (aff. podicipinus) chromosome 7 was relatively large and was the $5^{\text {th }}$ in size. Leptodactylus marmoratus had $2 \mathrm{n}=24, \mathrm{FN}=34$, and a karyotype formed by six large- and medium-sized pairs and six small pairs (Figure $1 \mathrm{H}$ ). Among these, pairs 1 and 5 were metacentric; pairs 2 and 3 were submetacentric; pair 4 was subtelocentric; and the remaining pairs 6 to 12 were telocentric.
Secondary constrictions were sporadically observed on chromosome 8 of L. chaquensis, L. labyrinthicus, L. rhodomystax, L. pentadactylus, and L. podicipinus, at the terminal short arm or, in the case of the latter species, at the proximal long arm. Leptodactylus chaquensis and $L$. rhodomystax also exhibited secondary constriction on the short arms of chromosome pairs 5 and 3, respectively. Chromosome 4 of $L$. petersii and Leptodactylus sp. (aff. podicipinus) showed secondary constriction at the proximal region on the long arm. Leptodactylus marmoratus 


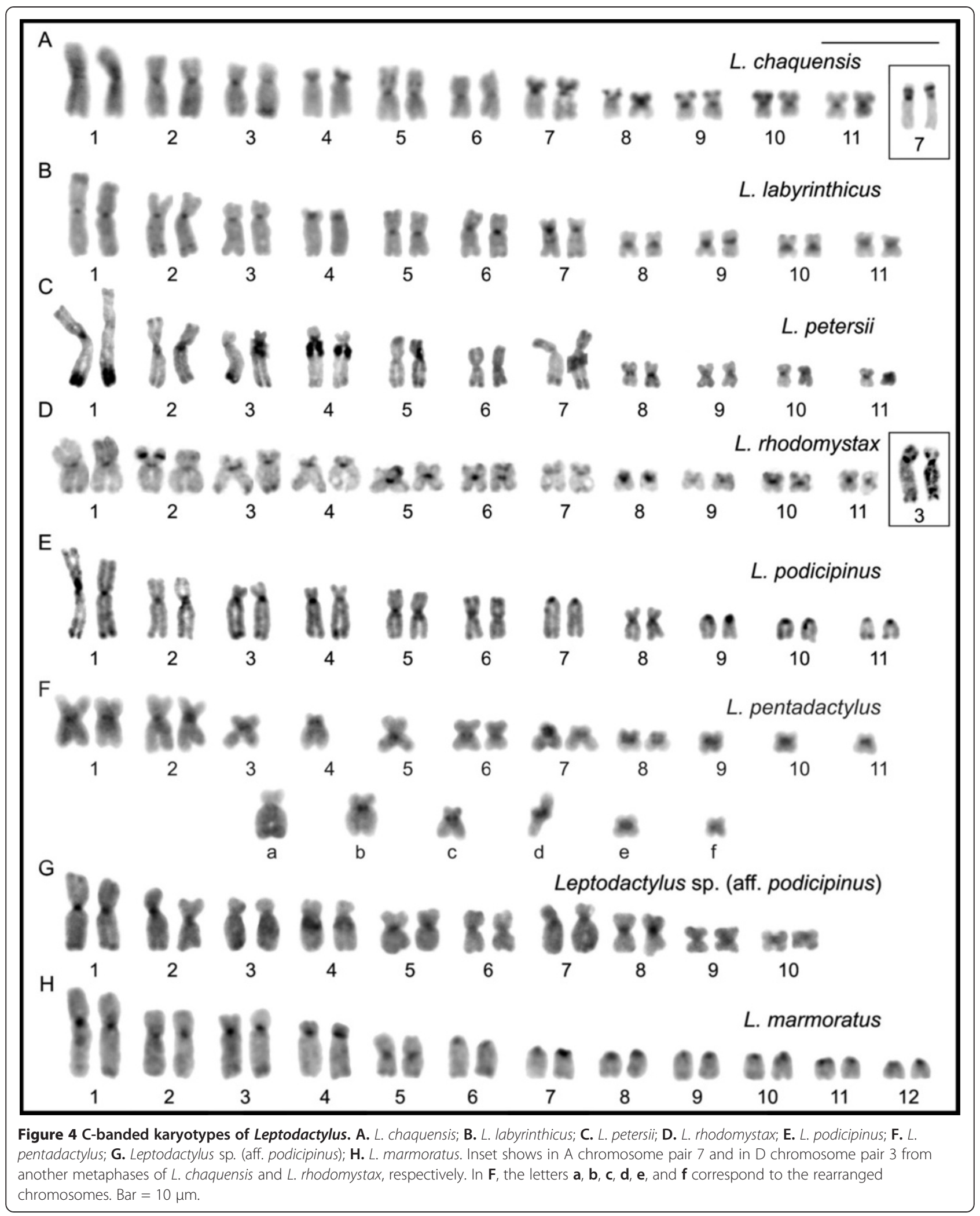


occasionally showed this marker only at the proximal region of the long arm of the telocentric chromosome 6 .

Male meiotic cells from all species except L. rhodomystax, in which there was no adult male available, were analysed. The cells from species with karyotypes of $2 n=22$, with exception of L. pentadactylus, had 11 bivalents during metaphase I, as shown for L. podicipinus in Figure 2A, and 11 chromosomes during metaphase II. Cells from L. pentadactylus in metaphase I had five bivalents, presumably corresponding to pairs $1,2,6,7$, and 8 , and a ring-shaped chain formed by 12 chromosomes, presumably corresponding to the elements $3,4,5,9,10,11, \mathbf{a}, \mathbf{b}$, c, d, e, and f (Figure 2B). In metaphase II, 11 chromosomes were observed, and as seen in Figure $2 \mathrm{C}$, the constitution of each cell could be distinguished. In both cells there was one element from the pairs $1,2,6,7$, and 8 , and one of the cells contained additionally chromosomes 3,4 , $5,9,10$, and 11 , while the other cell contained the chromosomes a, b, c, d, e, and f. Cells in metaphase I from Leptodactylus sp. (aff. podicipinus) had 10 bivalents (Figure 2D) and cells in metaphase II had 10 chromosomes. Cells in metaphase I from L. marmoratus had 12 bivalents (Figure 2E) and cells in metaphase II had 12 chromosomes.

\section{Conventional banding and molecular cytogenetics}

The techniques of Ag-NOR (Figure 1) and FISH using an rDNA probe (Figure 3) revealed that there was a single NOR-pair located on chromosome pair 8 of L. chaquensis, L. labyrinthicus, L. podicipinus, and L. pentadactylus. In metaphase I cells from $L$. pentadactylus the rDNA probe hybridised to one of the bivalents, which identified it as the bivalent 8 (Figure 3G). In L. rhodomystax, the NOR was on chromosome 3, whereas in L. petersii and Leptodactylus sp. (aff. podicipinus) the NOR was on chromosome 4. Multiple NORs occurred in L. marmoratus that showed Ag-labelling and probe hybridisation at the proximal regions of the long arms of the chromosomes 6 and 8. Heteromorphic NORs were observed in Leptodactylus sp. (aff. podicipinus) and the larger Ag-NOR frequently appeared as a duplicated block (Figure 1G). FISH using an rDNA probe confirmed that the Ag-NOR heteromorphism was due to the size of the transcriptional segment and not to a differential genetic activity (Figures 1G, $3 \mathrm{H})$. The sites of NOR were coincident with secondary constrictions in most cases.

All of the Leptodactylus species had a predominantly centromeric distribution of C-banded heterochromatin (Figure 4). The NOR sites and, less frequently, the interstitial, terminal, or telomeric regions of some chromosomes also appeared to have C-band which was particularly evident in some species. For example, in L. chaquensis, C-bands were observed at the interstitial regions of the short arms of chromosomes 4 and 7, easily detected when the chromosomes were less condensed (Figure 4A). In L. petersii, C-bands were evident at the terminal long arm of chromosome 1 and in both terminal short and long arms of chromosome 7 (Figure 4C). In L. rhodomystax, C-bands were detected interstitially on the short arm of chromosome 2, in heteromorphic condition, and were occasionally detected at the interstitial short arm of chromosome 3 (Figure 4D). Furthermore, C-positive staining was also detected at the site coinciding with the negative heteropycnotic region on the short arms of the chromosome 5 in L. chaquensis and chromosome 8 in L. rhodomystax.

The $\mathrm{CMA}_{3}$ staining exhibited brilliant fluorescence at the NOR sites for all of the species, as shown in Figure 5A-C for L. rhodomystax, L. podicipinus, and $L$. pentadactylus. These three species, along with $L$. petersii (data not shown), had additional $\mathrm{CMA}_{3}$ fluorescent labelling: in L. rhodomystax, at the interstitial short arms of chromosomes 2, 3, and other large- or medium-sized non-identified chromosomes and at the terminal region of a number of small-sized chromosomes, including the short arm of chromosome 8; in L. podicipinus, at the centromeric regions of all of the telocentric chromosome pairs and at the proximal region of chromosome 8; in L. pentadactylus, at the centromeric, interstitial, and terminal regions of some chromosomes, predominantly small-sized chromosomes; and in L. petersii, at the centromeric or terminal regions of some small-sized chromosomes, although the fluorescence was very faint. With DAPI staining, bright regions were not observed in most of the species. However, fluorescence was observed in the centromeric regions of some L. pentadactylus chromosomes (Figure 5D).

Using replication banding, homologous pairs were identified in each species (Figure 6). The replication banding patterns for chromosomes 1 to 11 were equivalent among the species L. chaquensis, L. labyrinthicus, and L. rhodomystax. Even though the banding differentiation in the small-sized chromosomes was poor, each of them had approximately the same patterns among the species. The comparison of the banded karyotype of L. petersii and of these three species also indicated no noticeable differences for the majority of the chromosomes. Figure 7A showed correspondence in the replication banding patterns of chromosomes 4, 5, and 6 in L. petersii, L. labyrinthicus, and L. podicipinus. There was also great banding correspondence between chromosomes 7 of L. petersii and L. labyrinthicus, but an additional late replicating band was visualised both in terminal short and long arms of the chromosome 7 in L. petersii (Figure 7A), corresponding to the heterochromatin region.

A comparison of banded chromosomes from L. podicipinus and L. labyrinthicus (Figure 7B) revealed that the replication banding patterns for chromosomes 1, 2, 3, 4, 5, 6, and 8 were equivalent between the two species. The uni- 
armed chromosomes 7, 9, 10, and 11 in L. podicipinus differed from the bi-armed chromosomes in L. labyrinthicus due to pericentric inversions. However, a better evidence of this rearrangement concerning the pair 11 was observed when the L. podicipinus chromosome 11 was compared with chromosome 11 of $L$. chaquensis.

The banding pattern analysis for L. pentadactylus confirmed that chromosomes $1,2,6,7$, and 8 existed in pairs and identified the chromosomes $3,4,5,9,10,11, \mathbf{a}, \mathbf{b}, \mathbf{c}$, $\mathbf{d}, \mathbf{e}$, and $\mathbf{f}$ as involved in rearrangements (Figure 6F). The chromosomes 1 to 11 of this species had the same replication banding patterns of the chromosomes 1 to 11 of L. rhodomystax (Figure 7C). In Figures $8 \mathrm{~A}$ and $8 \mathrm{~B}$, the multiple translocations in L. pentadactylus and the position of these chromosomes in the meiotic ring-shaped chain (Figure 8C) were tentatively shown in schematic drawings.

The replication banding patterns on chromosomes 1, 2, 3, 4, 5, 6, 9, and 10 of Leptodactylus sp. (aff. podicipinus) $(2 \mathrm{n}=20)$ matched the patterns on chromosomes $1,2,3$, $4,5,6,9$, and 11 of L. chaquensis $(2 \mathrm{n}=22)$, respectively (Figure 7D). The chromosomes 7 of these both species had equivalent banding pattern, but in Leptodactylus sp. (aff. podicipinus) the long arm of this chromosome was relatively longer than the long arm of the chromosome 7 in L. chaquensis. The long and short arms of chromosome 8 of Leptodactylus sp. (aff. podicipinus) matched the chromosomes 8 and 10 of L. chaquensis, respectively. As shown in Figure 7E, chromosomes 1 to 4 and chromosome 10 of L. marmoratus $(2 \mathrm{n}=24)$ had the same replication banding patterns as chromosomes 1 to 4 and chromosome 11 of $L$. podicipinus $(2 \mathrm{n}=22)$, respectively. Chromosomes 5 of both species had similar patterns, although partially, that is, chromosome 5 of L. marmoratus had correspondence with the short arm and proximal long arm of chromosome 5 of $L$. podicipinus. The telocentric chromosome 8 in L. marmoratus matched the submetacentric chromosome 8 in L. podicipinus, considering the chromosome of this latter species upside-down in Figure 7E.

The telomeric probe hybridised with the chromosome ends in all species, as shown for L. pentadactylus, $L$. podicipinus, Leptodactylus sp. (aff. podicipinus), and $L$. marmoratus in Figures 9A-D respectively. In these three latter species, however, the chromosomes also exhibited hybridisation signals outside of the telomere region: for L. podicipinus in the centromeric regions on chromosomes 1 and 2 and on some of the other large- and medium-sized chromosomes; for Leptodactylus sp. (aff. podicipinus) in the centromeric region on one of smallsized chromosome pairs, even though the signal was very slight; and for L. marmoratus in the centromeric region on chromosome 1 and most probably in the centromeric region on telocentric pair 6. In meiotic preparations of L. pentadactylus, FISH with the telomeric probe could be obtained and in the initial meiotic nuclei fluorescent labelling appeared polarised as result of the bouquet configuration of the chromosomes (Figure 9E).

\section{Discussion}

Among the analysed species of Leptodactylus six had $2 \mathrm{n}=22$ and two others had $2 \mathrm{n}=20$ or $2 \mathrm{n}=24$. Only $L$. chaquensis, L. labyrinthicus, and L. rhodomystax shared approximately the same basic karyotype of the genus with 22 bi-armed chromosomes. The similarity in the chromosome constitutions of these three species was also supported by the equivalence in the replication banding patterns of each chromosome pair. These data confirmed previous conclusions that, at least the largest chromosomes and the NOR-bearing chromosome 8 in several species had equivalent replication banding patterns [16-19]. Although L. petersii had the same 2n and FN of L. chaquensis, L. labyrinthicus, and L. rhodomys$\operatorname{tax}$, there was minor karyotype discrepancy regarding the relative size of pair 7 . Nevertheless, the comparison of replication banding patterns confirmed the almost complete homeology between the chromosomes 7 of $L$. petersii and L. labyrinthicus. The difference was in the presence of an additional late replicating band, both in the short and in the long arms of chromosome 7 of L. petersii, which were shown to contain C-banded heterochromatin.

Leptodactylus podicipinus had an indistinguishable karyotype to those previously described for the species $[16,20,33]$ and the most prominent feature was the presence of four pairs of telocentric chromosomes. Taking into consideration that the morphology of some chromosome pairs in L. podicipinus has been altered without changing the diploid number, it had been suggested that pericentric inversions might be responsible for such karyotype divergence [16]. Among the Leptodactylus species where $2 \mathrm{n}=22$ and some uni-armed chromosomes, L. podicipinus was the first case in which the replication banded telocentric chromosomes could be compared with the presumed homeologous bi-armed elements of L. labyrinthicus. The findings from the present analysis confirmed the hypothesis that pericentric inversion resulted in changes to the morphologies of chromosomes 7, 9, 10, and 11 in both species.

Even though L. pentadactylus had $2 \mathrm{n}=22$ with biarmed chromosomes, the karyotype was one of the most intriguing, because only chromosomes $1,2,6,7$, and 8 could be accurately paired. With standard staining, chromosomes 3, 4, 5, a, b, c, and $\mathbf{f}$ did not have recognisable homologues and these four latter elements had no corresponding chromosomes identified among the species with basic karyotypes of $2 \mathrm{n}=22$ that matched them in either morphology or size. Chromosomes 9, 10, 11, 


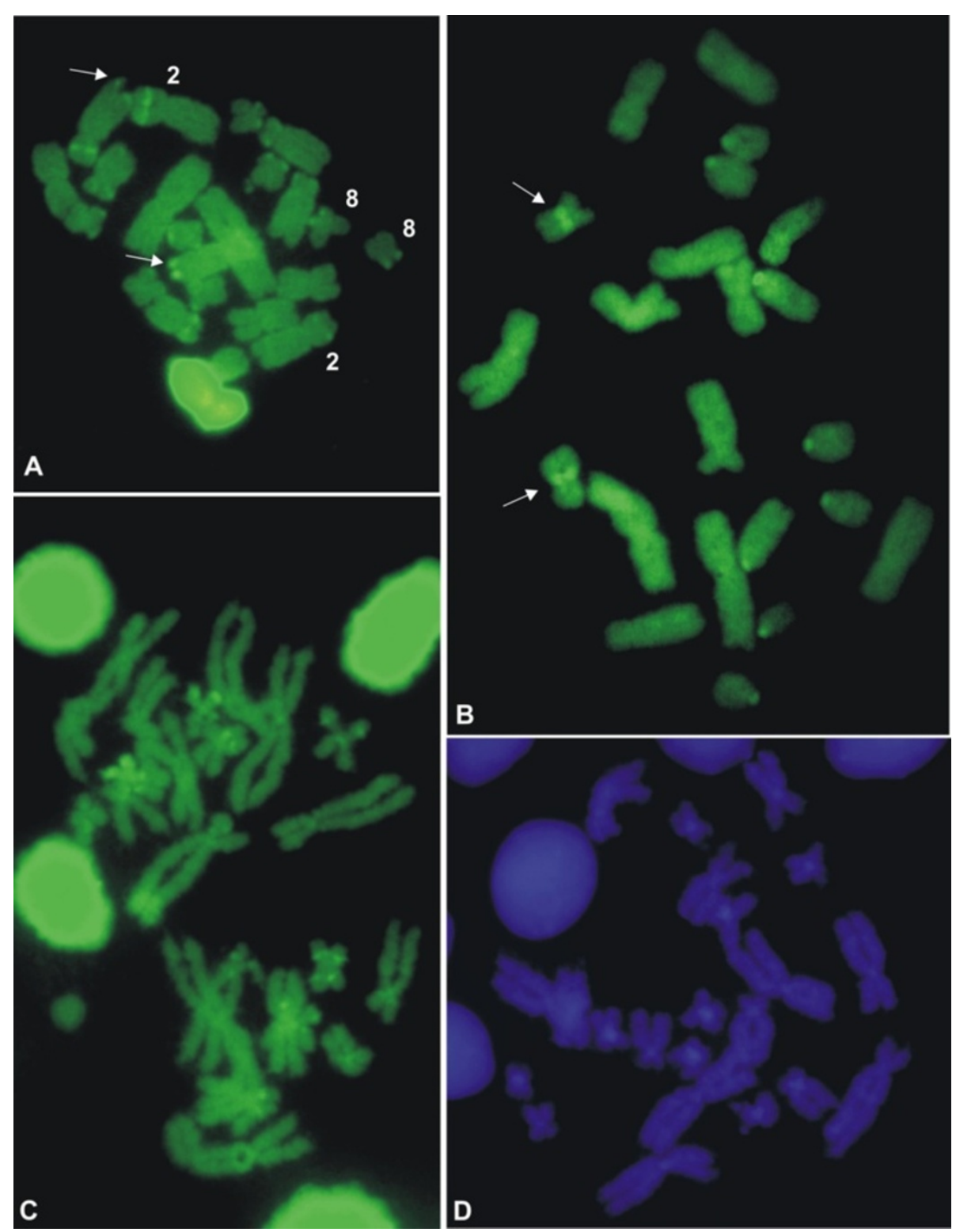

Figure 5 Fluorochrome-stained metaphase cells of Leptodactylus. A. $\mathrm{CMA}_{3}$ in L. rhodomystax; $\mathbf{B}$. $C M \mathrm{~A}_{3}$ in L. podicipinus; C. CMA 3 and D. DAPI in L. pentadactylus. Arrows in A an B indicate NOR-bearing chromosomes. Bar $=10 \mu \mathrm{m}$.

d, and e could be tentatively paired based on morphological similarities, but one of them would remain without a homologue, supporting our suggestion that L. pentadactylus has a complex chromosome constitution. The meiotic analysis confirmed that multiple translocations are responsible for this unusual, but balanced karyotype. A ring-shaped chain formed by 12 chromosomes in addition to five bivalents in the metaphase I cells discarded the possibility of pairing between the repetitive sequences located in the terminal regions of the chromosomes. According to Schmid et al. [34], the nonchiasmatic ectopic pairing could be responsible for the formation of a meiotic chain observed in some analysed anuran species [35-37].

In natural populations of vertebrate, one example of species where meiotic chain was formed as result of multiple translocations is monotreme Ornithorhynchus anatinus. This species carries a multiple sex chromosome system of $\mathrm{X}_{1} \mathrm{Y}_{1} \mathrm{X}_{2} \mathrm{Y}_{2} \mathrm{X}_{3} \mathrm{Y}_{3} \mathrm{X}_{4} \mathrm{Y}_{4} \mathrm{X}_{5} \mathrm{Y}_{5}: \mathrm{X}_{1} \mathrm{X}_{1} \mathrm{X}_{2} \mathrm{X}_{2} \mathrm{X}_{3} \mathrm{X}_{3} \mathrm{X}_{4} \mathrm{X}_{4} \mathrm{X}_{5} \mathrm{X}_{5}$ type [38] and during meiosis of males alternate segregation occurs, which ensures balanced gametes with $\mathrm{X}$ or $\mathrm{Y}$ chromosomes. The chromosomes of the ring chain in L. pentadactylus male may undergo an alternate segregation, giving rise to two types of normal gametes, yet with rearranged 


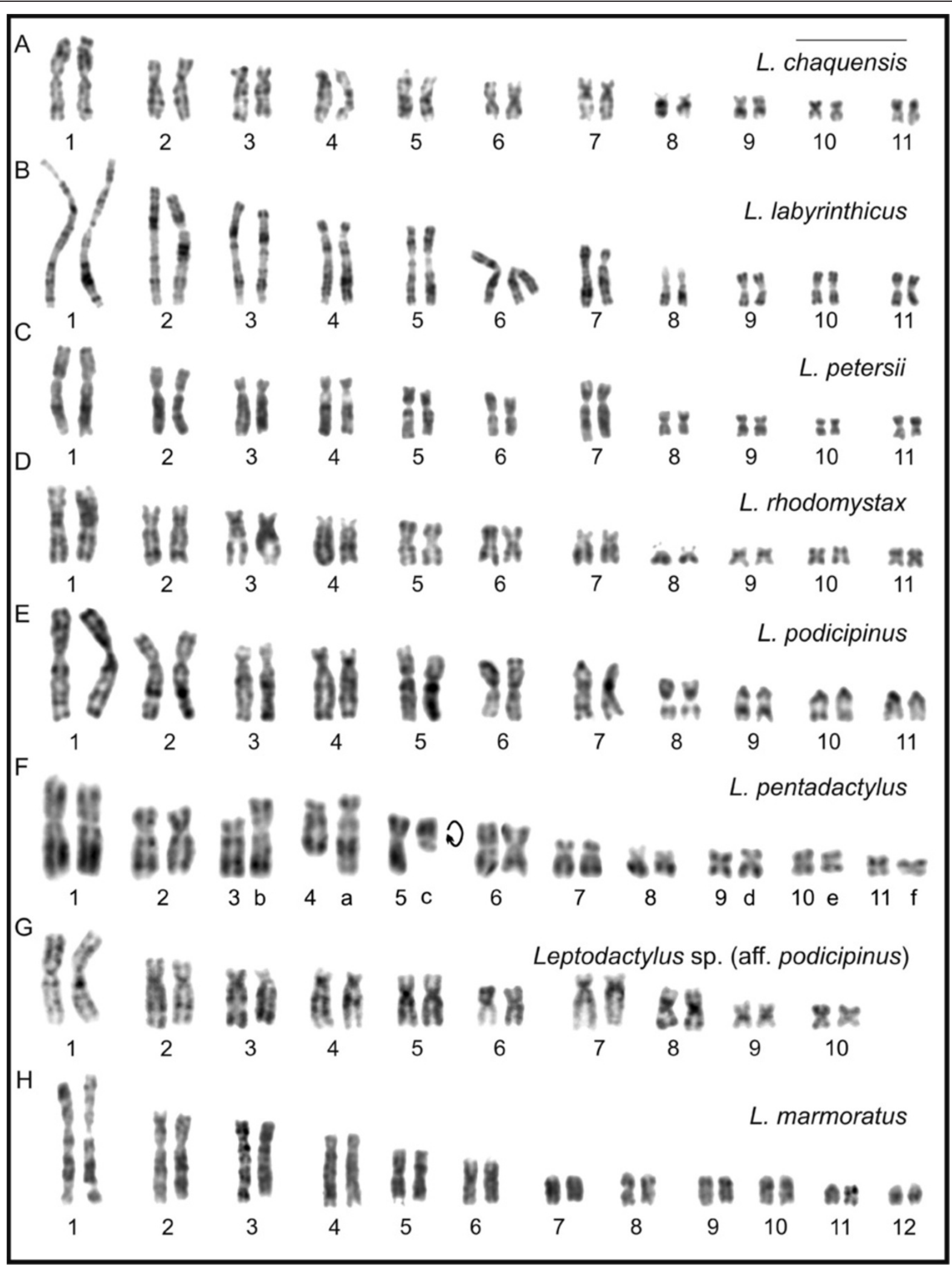

Figure 6 (See legend on next page.) 
(See figure on previous page.)

Figure 6 Replication-banded karyotypes of Leptodactylus, after BrdU incorporation. A. L. chaquensis; B. L. labyrinthicus; C. L. petersii; D. L. rhodomystax; E. L. podicipinus; F. L. pentadactylus; G. Leptodactylus sp. (aff. podicipinus); H. L. marmoratus. In F, the letters $\mathbf{a}, \mathbf{b}, \mathbf{c}, \mathbf{d}, \mathbf{e}$, and $\mathbf{f}$ correspond to the rearranged chromosomes. Bar $=10 \mu \mathrm{m}$.

chromosome constitution in one of them, as it was illustrated in Figure 2C. Our observation of two types of metaphase II cells, which likely originated from the same spermatocyte II, is according to an alternate segregation. Currently, however, adjacent segregations of the chromosomes have not been excluded and need to be investigated.

The replication banding pattern in the sampled L. pentadactylus collected from Paranaíta confirmed the uniqueness of the chromosome constitution, originated as a result of rare multiple rearrangements. An apparently normal karyotype with 22 bi-armed chromosomes was previously obtained for L. pentadactylus from both Peru and the state of São Paulo in southeastern Brazil
[33]. Nevertheless, the sample from Brazil does not correspond to $L$. pentadactylus because its known distribution is limited to the Amazon forest in the northern part of South America [1]. In another study, a karyotype of $2 n=22$ with heteromorphic reciprocal translocation was described for one juvenile specimen from Cláudia, a locality also in central Brazil, but authors [17] suggested that the rearrangement was produced during the fibroblast culture. Larger samples of $L$. pentadactylus from Paranaíta and vicinities, including specimens from Cláudia, should be karyotyped to test the hypothesis that heteromorphic multiple chromosome rearrangements are fixed or not in the populations, or whether other karyotype constitutions occur for the species.

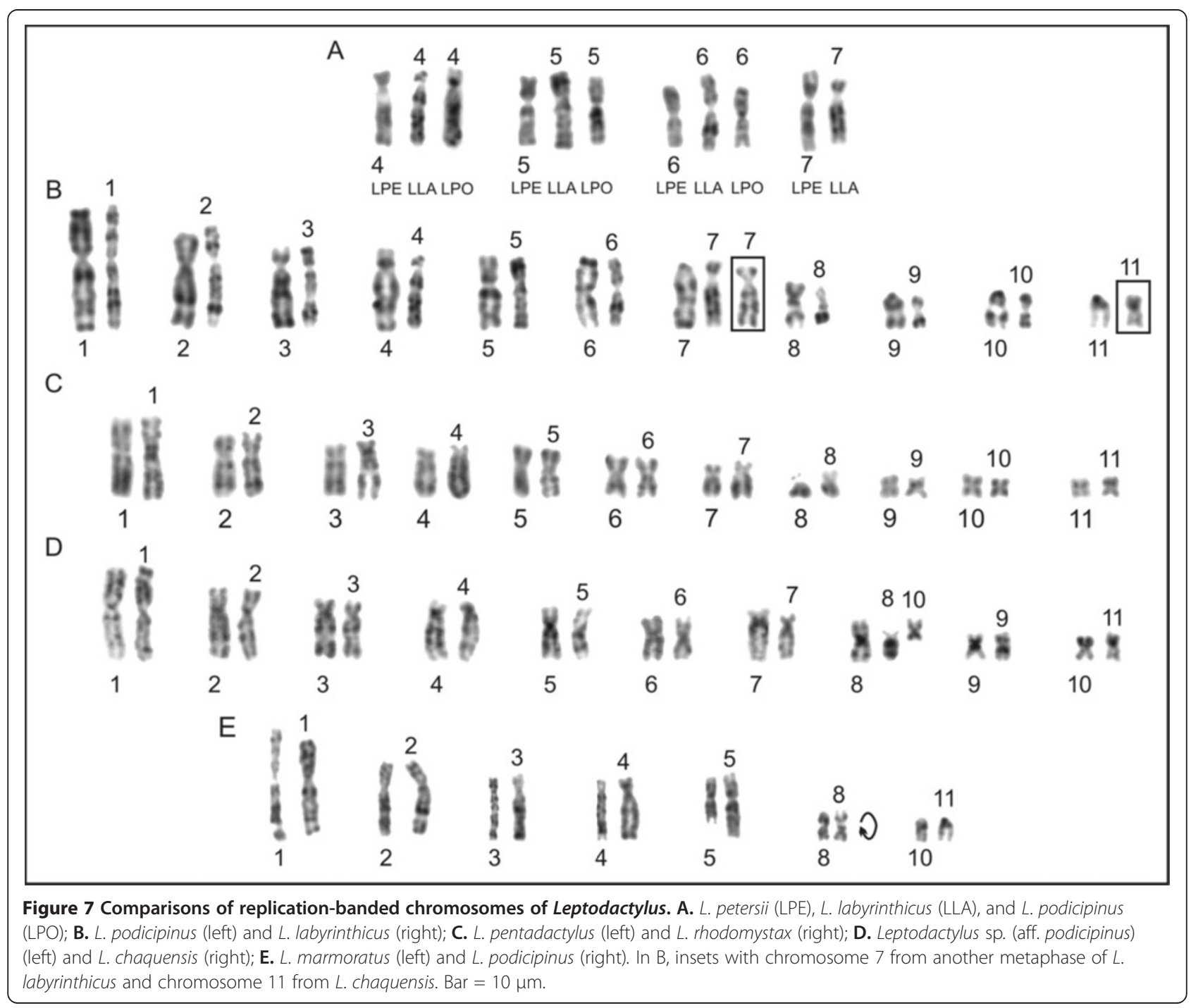




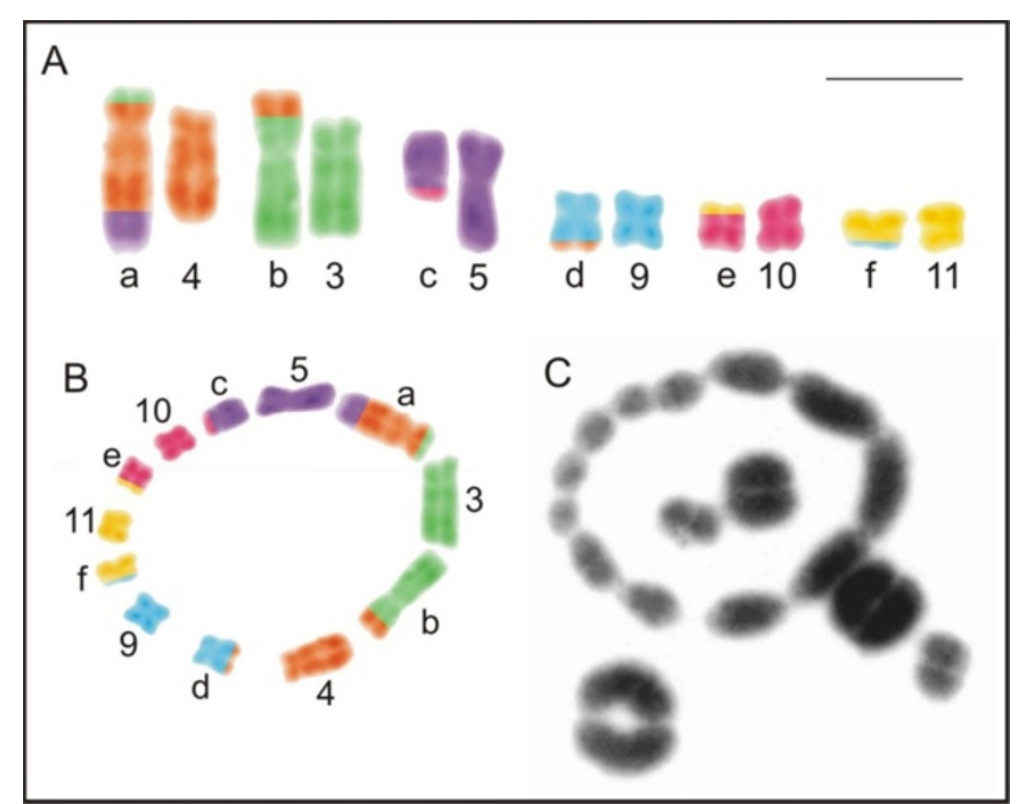

Figure 8 Tentative identification of the multiple translocations in Leptodactylus pentadactylus. A. schematic drawings of mitotic banded chromosomes and $\mathbf{B}$. the chromosomes in meiotic chain; $\mathbf{C}$. meiotic chain from metaphase I cell. The letters $\mathbf{a}, \mathbf{b}, \mathbf{c}, \mathbf{d}$, e, and $\mathbf{f}$ correspond to the rearranged chromosomes. Bar $=10 \mu \mathrm{m}$.

The distinguishing feature in the karyotype of Leptodactylus sp. (aff. podicipinus) where $2 \mathrm{n}=20$ was the absence of two small-sized chromosome pairs and the presence of relatively larger chromosome pairs 7 and 8 , when compared with the basic conserved Leptodactylus karyotype of $2 n=22$. Correspondence between the replication banding patterns for the majority of the chromosomes of Leptodactylus sp. (aff. podicipinus) with the chromosomes of $L$. chaquensis where $2 \mathrm{n}=22$ was demonstrated. The comparative analysis confirmed the hypothesis that the reduction in the diploid number to $2 \mathrm{n}=20$ was the result of fusion between two small-sized elements, probably the chromosomes 8 and 10 in L. chaquensis giving rise to the chromosome 8 of Leptodactylus sp. (aff. podicipinus). The chromosomes 7 of both species had the same replication banding, but in Leptodactylus sp. (aff. podicipinus) the long arm of this chromosome is longer, may be because of the accumulation of repetitive sequences. Nevertheless, there was not evidence that these sequences were $\mathrm{C}$-banded, as observed in the chromosome 7 of L. petersii.

To our knowledge, the karyotype with $2 \mathrm{n}=20$ of Leptodactylus sp. (aff. podicipinus) is new for the genus, not previously described. A detailed analysis, including characterisations of morphological traits, reproductive behaviours, vocalisations, geographical distribution, sequencing of molecular markers, and other characters of this taxon, should be conducted to investigate whether we are dealing or not with a new undescribed species. Interestingly, even though Leptodactylus sp. (aff. podicipinus) and $L$. petersii have distinct chromosome numbers, they have NORs located in the same site of the chromosome 4, this feature representing a synapomorphic condition for both species.

The karyotype of L. marmoratus was identical to those previously described $[13,33]$ for specimens collected from the state of São Paulo. However, the first authors [13] did report population difference in morphology of the smallest chromosome pair, suggesting occurrence of pericentric inversion. Despite the similarities between the karyotypes of L. marmoratus $(2 \mathrm{n}=24)$ and L. podicipinus $(2 \mathrm{n}=22)$ regarding the first chromosome pairs and presence of telocentric chromosomes in both species, only a few chromosomes conserved the same replication banding patterns. These findings suggest that most of the chromosomes may have undergone great reorganization, which could not be detected in the banding comparisons. Nevertheless, the distinct chromosome numbers in both species most likely involved fusion between chromosome 5 and a small non-identified element in an ancestral karyotype equivalent to that of $L$. marmoratus or a chromosome fission of the chromosome 5 in an ancestral karyotype equivalent to that of $L$. podicipinus. Possible complex chromosome rearrangements or simple centromere repositioning which alters the chromosome morphology could not be identified because of the limited resolution of the techniques. An important question addresses the controversial systematics of Adenomera that, along with Lithodytes, were assigned within Leptodactylus according to the molecular phylogenetic trees of Frost et al. [3] and Grant et al. 


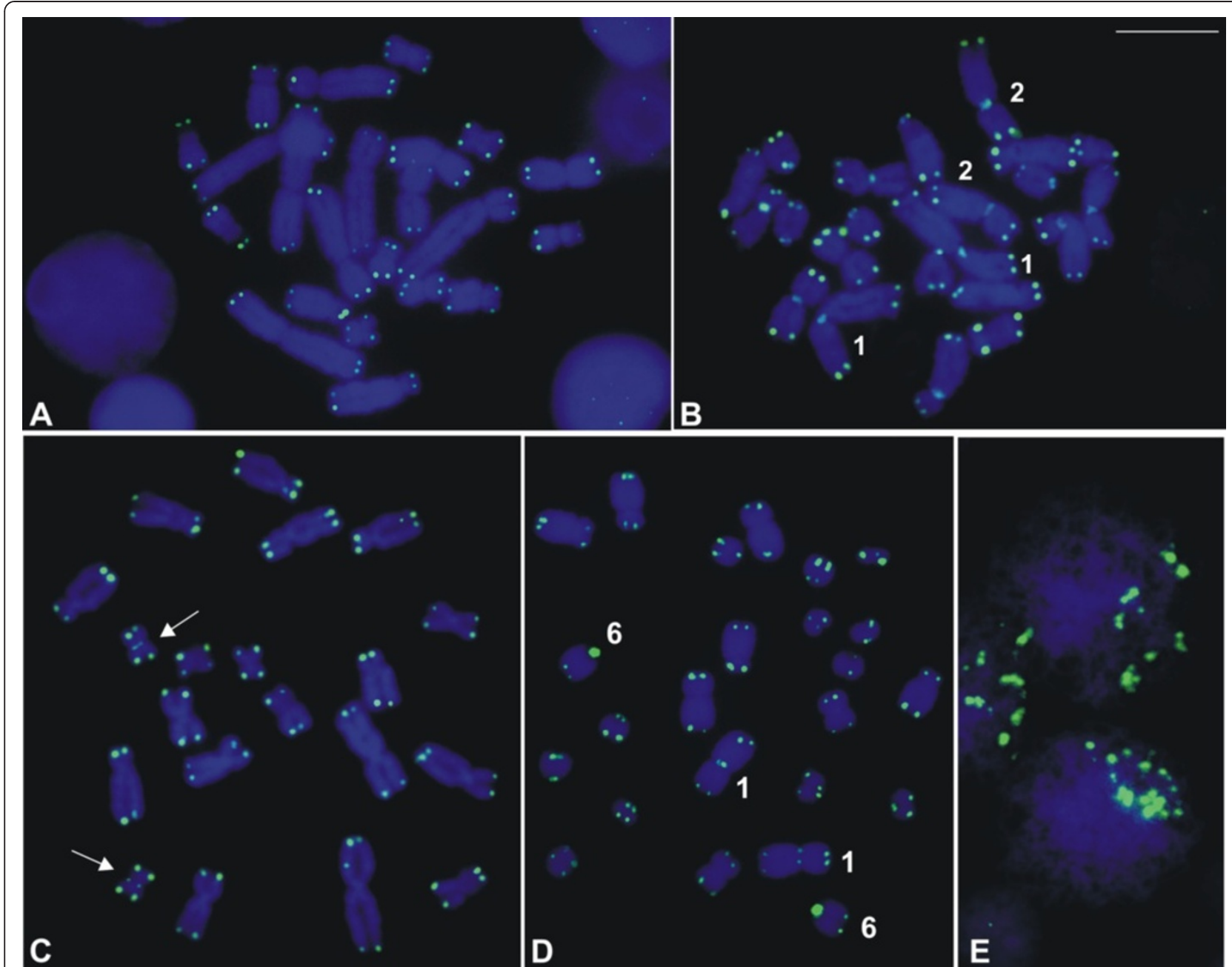

Figure 9 FISH using a telomeric probe in Leptodactylus. A. mitotic metaphase of L. pentadactylus; B. mitotic metaphase of L. podicipinus; C. mitotic metaphase of Leptodactylus sp. (aff. podicipinus); D. mitotic metaphase of L. marmoratus; E. initial meiotic nuclei of L. pentadactylus showing polarisation of the telomeric labelling. Note the centromeric hybridisation signals in chromosomes 1, 2, and other unidentified largeand medium-sized chromosomes in B; in chromosomes of one small-sized pair (arrows) in C; and in chromosomes 1 and in telocentric chromosomes 6 in D. Bar $=10 \mu \mathrm{m}$.

[4]. Recently, both were again considered to be valid genera of the family Leptodactylidae by Pyron and Wiens [6]. The molecular data by Silva et al. [unpublished data] support the first two reports recovering the monophyletic condition for Leptodactylus including Adenomera and Lithodytes. Even though the comparison of the replication-banded karyotypes of $L$. marmoratus and L. podicipinus could establish some chromosome homeology, it does not contribute to new insights into their chromosome evolution, which have been discussed in the literature [13,33,39].

In the sampled species, the combined use of silver impregnation and FISH using an rDNA probe confirmed that the majority of the secondary constrictions were active NORs. The negative heteropycnotic sites in chromosome 5 of $L$. chaquensis and in chromosome 8 of L. rhodomystax, which could indicate inactive nucleolar organiser regions, were excluded as true NORs. Both of the regions were $\mathrm{C}$-positive and may represent species-specific repetitive sequence sites. A single pair of NORs occurs frequently among the Leptodactylus species, usually on the chromosome 8 , although at distinct sites [11,16-18], as here observed in L. chaquensis, L. labyrinthicus, L. pentadactylus, and L. podicipinus. Less frequently, NORs are on largesized chromosomes, such as the chromosome 3 in L. rhodomystax and the chromosome 4 in L. petersii and Leptodactylus sp. (aff. podicipinus). In L. mystacinus, NOR was found at the terminal short arm of chromosome pair 4, in addition to a NOR found on chromosome 8 [19]. In our samples, multiple NORs were confirmed in L. marmoratus, which had NORs located on telocentric 
chromosomes 6 and 8. This finding differed from previous data for this same species collected in distinct locations, in which a single Ag-NOR pair on chromosome 6 was observed, although one specimen showed an additional Ag-NOR on chromosome 8 [13]. Our data strongly suggest that the NOR on chromosome 8 may be an ancestral characteristic for the genus Leptodactylus and that even when the NOR is absent, as in $L$. rhodomystax, a vestige of this site remains, as evidenced by the C-banded heterochromatin at the short arm of chromosome 8, which showed brilliant $\mathrm{CMA}_{3}$ fluorescence.

Changes in the NOR site in Leptodactylus species were not the result of gross structural rearrangements because the chromosomes had the same replication banding patterns, regardless of whether they carried or not the rDNA sequence. Even the telocentric chromosome 8 of L. marmoratus had a replication pattern that was indistinguishable from the submetacentric chromosome 8 of L. podicipinus. The replication banding pattern of the chromosome 8 appears to be independent of the chromosome morphology and location of the NOR (i.e., at the short or long arm) which is characteristic of centromere repositioning. Nevertheless, minor structural rearrangements, such as reciprocal translocations or pericentric inversions, involving only the rDNA sequences, along with transpositions by mobile elements, cannot be disregarded.

The C-banding patterns were predominantly centromeric, although with some interstitial or terminal labelling, such as in L. chaquensis, L. petersii, and in L. rhodomystax. Interspecies differences in C-banding patterns, or even among distinct populations of the same species, may exist [16-18] although these findings should be considered with care because of variations in C-banding produced during technical procedures. In L. chaquensis males, a sub-centromeric C-band was not observed in either chromosome 1, discarding XY chromosome differentiation, as previously reported for the Argentinean specimens [15]. The cytogenetic information on repetitive sequences in the Leptodactylus species was improved by combining the $\mathrm{C}$-banding technique with other procedures, such as stainings with AT- or GC-specific fluorochromes. These techniques not only revealed the molecular contents but also provided information on the occurrence of repetitive DNA sites, not detected by Cbanding technique, as in the case of L. pentadactylus. In this species, although a centromeric C-banding pattern was noticed, $\mathrm{CMA}_{3}$ staining revealed repetitive sites out the centromeric region. Furthermore, the results using one or both fluorochromes evidenced that some patterns were species-specific, such as for L. chaquensis, L. pentadactylus, L. petersii, L. podicipinus, and L. rhodomystax. The FISH technique using a telomeric probe could be another useful tool for characterising the heterogeneity of some repetitive regions, such as in $L$. marmoratus, $L$. podicipinus, and Leptodactylus sp. (aff. podicipinus). In these species, the hybridisation signal was not only observed in telomere regions but was also in the centromeric regions of some chromosomes, which indicates that repetitive sequences similar to the telomeric sequence (TTAGGG) are present outside of the telomere-ends as it has been reported for other vertebrates, including frogs [40-43]. For all the remaining species of this study no interstitial telomeric signal was evident, even in the cases where structural rearrangements are presumed to have occurred during chromosome evolution, similarly to that observed in rodent species, whose karyotypes differed by fusion/fission events [44]. Nevertheless, the possibility that the centromeric labelling in a chromosome pair of small size, the 9 or the 10, in Leptodactylus sp. (aff. podicipinus) is a telomere remnant cannot be discarded because the corresponding chromosomes in some species of Leptodactylus, such as in L. podicipinus, differed by a pericentric inversion.

\section{Conclusions}

Although the high karyotype similarity in most of the eight species of Leptodactylus, major and minor karyotype differences were evident using classical and molecular cytogenetic techniques. Discrepancies were observed in the morphology of some chromosomes, including the presence of telocentric chromosomes, the occurrence of multiple translocations, the distinct localisation of secondary constrictions, whether true NORs or not, and the molecular nature of some of the repetitive sequences. The replication banding after BrdU incorporation, which is one of the unique procedures to provide reproducible multiple bands throughout amphibian chromosomes, was fundamental for confirming the karyotype differences. This relatively little timeconsuming technique allowed us to outline the mechanisms responsible for several karyotype differences, some of them never described before. Nevertheless, more species should be analysed using other approaches (e.g., cross-chromosome painting and linkage analysis), especially if they are combined with taxonomic data and phylogenetic trees based on distinct characters. Currently, the accumulation or loss of repetitive DNA sequences [45] cannot be ignored. Mapping this information on the chromosomes is essential for detailed karyotype comparisons and for enlightenment of chromosome evolution.

\section{Additional file}

Additional file 1: List of karyotyped species of Leptodactylus, number of individuals, sex, voucher number, and collecting locations in Brazil. 


\section{Abbreviations}

2n: Diploid number; Ag-NOR: Nucleolar organiser region marked by silver staining; BrdU: 5-bromodeoxyuridine; $\mathrm{CMA}_{3}$ : Chromomycin $\mathrm{A}_{3}$; DAPI: 4'-6diamidino-2-phenylindole; FISH: Fluorescence in situ hybridisation: FPG: Fluorochrome plus Giemsa; FN: Fundamental number of chromosome arms; NOR: Nucleolar organiser region; rDNA: Ribosomal DNA.

\section{Competing interests}

The authors of this manuscript declare that they have no competing interests.

\section{Authors' contributions}

TG performed the cytogenetic analyses during his postgraduate course. SLG assisted in the FISH experiments and in the preparation of the final figures. APZS helped draft the manuscript and participated in the final revisions of the text. OGSA and HN collected animals and helped with identification. CS provided animals and revised the manuscript. CFBH helped with specimen identification and revisions to the manuscript. SK supervised the cytogenetic studies, the drafting of the manuscript, and the revision of the final text. All authors have read and approved the final text.

\section{Acknowledgements}

The authors are deeply grateful to the Conselho Nacional de Desenvolvimento Científico e Tecnológico (CNPq), Fundação de Amparo à Pesquisa do Estado de São Paulo (FAPESP), Fundação de Amparo à Pesquisa do Estado de Mato Grosso (FAPEMAT, process \#40265/2009 to CS), and Fundação Oswaldo Cruz (FIOCRUZ) for their financial supports and scholarships. They thank Instituto Chico Mendes de Conservação da Biodiversidade (ICMBio) for providing the collection permits to TG, OGSA, HN, CS, and CFBH. They are also grateful to Dr. Ricardo J Sawaya for providing one Leptodactylus labyrinthicus and to Álvaro D S Modesto for collecting one Leptodactylus petersii in Amapá, Brazil.

\section{Author details}

'Departamento de Biologia, Instituto de Biociências, Universidade Estadual Paulista, UNESP, Rio Claro, São Paulo, Brazil. ${ }^{2}$ Laboratório de Ecologia e Evolução, Instituto Butantan, São Paulo, São Paulo, Brazil. ${ }^{3}$ Departamento de Zoologia, Instituto de Biociências, Universidade Estadual Paulista, UNESP, Rio Claro, São Paulo, Brazil. ${ }^{4}$ Departamento de Ciências Básicas e Produção Animal, Faculdade de Agronomia, Medicina Veterinária e Zootecnia, UFMT, Cuiabá, Mato Grosso, Brazil.

Received: 29 August 2012 Accepted: 14 December 2012 Published: 26 December 2012

\section{References}

1. Frost DR: Amphibian Species of the World: an Online Reference. Version 5.5 . New York, USA: American Museum of Natural History; 2011. Electronic Database accessible at http://research.amnh.org/vz/herpetology/amphibia/.

2. Segalla MV, Caramaschi U, Cruz CAG, Garcia PCA, Grant T, Haddad CFB, Langone J: Brazilian amphibians - List of species. São Paulo, Brasil: Sociedade Brasileira de Herpetologia; 2012. Acessible at http://www.sbherpetologia.org.br/.

3. Frost DR, Grant T, Faivovich J, Bain RH, Haas A, Haddad CFB, De Sa RO, Channing A, Wilkinson M, Donnellan SC, Raxworthy CJ, Campbell JA, Blotto BL, Moler P, Drewes RC, Nussbaum RA, Lynch JD, Green DM, Wheeler WC: The amphibian tree of life. Bull Am Mus Nat His 2006, 297:1-370.

4. Grant T, Frost DR, Caldwell JP, Gagliardo R, Haddad CFB, Kok PJR, Means DB, Noonan BP, Schargel WE, Wheeler WC: Phylogenetic systematic of dartpoison frogs and their relatives (Amphibia: Athesphatanura: Dendrobatidae). Bull Am Mus Nat His 2006, 269:1-262.

5. Hedges SB, Duellman WE, Heinicke MP: New World direct-developing frogs (Anura: Terrarana): molecular phylogeny, classification, biogeography, and conservation. Zootaxa 2008, 1737:1-182.

6. Pyron RA, Wiens JJ: A large-escale phylogeny of Amphibia including over 2800 species, and a revised classification of extant frogs, salamanders, and caecilians. Mol Phylogenet Evol 2011, 61:543-583.

7. Ponssa ML, Heyer WR: Osteological characterization of four putative species of the genus Adenomera (Anura: Leptodactylidae), with comments on intra- and interspecific variation. Zootaxa 2007, 1403:37-54.
8. Kwet A, Steiner J, Zillikens A: A new species of Adenomera (Amphibia, Anura, Leptodactylidae) from the Atlantic Rain Forest in Santa Catarina, southern Brazil. Stud Neotrop Fauna Environ 2009, 44:93-107.

9. King M: Amphibia. In Animal Cytogenetics. Amphibia. Volume 4. Chordata 2. Edited by John B, Gwent C. Berlin: Gebrüder Borntraeger; 1990:1-241.

10. Kuramoto $\mathrm{M}: \mathrm{A}$ list of chromosome numbers of anurans amphibians. Bull Fukuoka Univ Educ 1990, 39:83-127.

11. Amaro-Ghilardi RC, Skuk G, De Sa RO, Rodrigues MT, Yonenaga-Yassuda Y: Karyotypes of eight species of Leptodactylus (Anura, Leptodactylidae) with a description of a new karyotype for the genus. Phyllomedusa 2006, 5:119-133.

12. Green DM, Sessions SK: Karyology and Cytogenetics. In Amphibian Biology. Volume 7. Edited by Heatwole H, Tyler M. Chipping Norton: Surrey Beatty and Sons; 2007:2756-2841

13. Campos JRC, Ananias F, Brasileiro CA, Yamamoto M, Haddad CFB, Kasahara S: Chromosome evolution in three Brazilian Leptodactylus species (Anura, Leptodactylidae), with phylogenetic considerations. Hereditas 2009, 146:104-111.

14. Zaracho VH, Hernando AB: The karyotype of Adenomera diptyx (Boettger 1885) (Anura, Leptodactylidae) from northeastern Argentina. Genet Mol Biol 2011, 34:84-87.

15. Barale GD, Senn EP, Lisanti JA: Polimorfismo de bandas $C$ ligado al sexo en Leptodactylus chaquensis (Anura, Leptodactylidae). Rev Univ Nac Río Cuarto 1990, 10:51-53.

16. Silva APZ, Haddad CFB, Kasahara S: Chromosomal studies on five species of the genus Leptodactylus Fitzinger, 1826 (Amphibia, Anura) using differential staining. Cytobios 2000, 103:25-38.

17. Amaro-Ghilardi RC, Rodrigues MT, Yonenaga-Yassuda YY: Chromosomal studies after differencial staining and fluorescence in situ hybridization using telomeric probe in three Leptodactylus species (Leptodactylidae, Anura). Caryologia 2004, 57:53-65.

18. Silva APZ, Garcia PCA, Martins VG, Bacci M: Chromosomal and molecular analyses of Leptodactylus gracilis gracilis, L. gracilis delattini, and $L$. plaumanni (Anura, Leptodactylidae): taxonomic implications. Amphib-Reptil 2004, 25:185-196.

19. Silva APZ, Haddad CFB, Galassi GG, Kasahara S: Multiple nucleolus organizer regions in Leptodactylus mystacinus (Amphibia, Anura) and comments on its systematic position in the L. fuscus group based on cytogenetic and molecular analyses. Genetica 2006, 127:35-44.

20. Arruda MP, Morielle-Versute E: Cytogenetic and random amplified polymorphic DNA analysis of Leptodactylus species from rural and urban environments (Anura, Amphibia). Genet Mol Res 2008, 7:161-176.

21. Bianchi NO, Molina JO: DNA replication patterns in somatic chromosomes of Leptodactylus ocellatus (Amphibia, Anura). Chromosoma 1967, 22:391-400

22. Bianchi NO, Bianchi MS, Vidal-Rioja L: Heterochromatin late replication and secondary constrictions in the chromosome complement of Leptodactylus ocellatus. Caryologia 1973, 26:397-403.

23. Baldissera FA Jr, Oliveira PSL, Kasahara S: Cytogenetics of four Brazilian Hyla species (Amphibia-Anura) and description of a case with a supernumerary chromosome. Rev Bras Genet 1993, 16:335-345.

24. Schmid M: Chromosome banding in Amphibia. I. Constitutive heterochromatin and nucleolus organizer regions in Bufo and Hyla. Chromosoma 1978, 66:361-388.

25. Kasahara S, Silva APZ, Gruber SL: Use of lymphocyte cultures for BrdU replication banding patterns in anuran species (Amphibia). Genet Mol Biol 1998, 21:471-476.

26. Howell WM, Black DA: Controlled silver-staining of nucleolus organizer regions with a protective colloidal developer: 1-step method. Experientia 1980, 36:1014-1015

27. Sumner AT: A simple technique for demonstrating centromeric heterochromatin. Exp Cell Res 1972, 75:304-306.

28. Dutrillaux B, Couturier J: La Pratique de l'Analyse Chromosomique. Paris: Masson; 1981

29. Christian A, McNiel E, Robinson J, Drabek J, LaRue C, Waldren C, Bedford J: A versatile image analyses approach for simultaneous chromosome identification and localization of FISH probes. Cytogenet Cell Genet 1998, 82:172-179.

30. Meunier-Rotival M, Cortadas J, Macaya G, Bernardi G: Isolation and organization of calf ribosomal DNA. Nucleic Acids Res 1979, 6:2109-2123.

31. Pinkel D, Straume T, Gray JW: Cytogenetic analysis using quantitative, high-sensitivity, fluorescence hybridization. Proc Natl Acad Sci USA 1986, 83:2934-2938. 
32. Green DM, Sessions SK: Nomenclature for chromosomes. In Amphibian Cytogenetics and Evolution. Edited by Green DM, Sessions SK. San Diego: Academic Press; 1991:431-432.

33. Bogart JP: A karyosystematic study of frogs in the genus Leptodactylus (Anura: Leptodactylidae). Copeia 1974, 3:728-737.

34. Schmid M, Steinlein C, Bogart JP, Feichtinger W, León P, La Marca E, Diaz LM, Sans A, Chen S-H, Hedges SB: The chromosomes of Terraranan frogs: insights into vertebrate cytogenetics. Cytogenet Genome Res 2010, 130-131:1-568.

35. Lourenço LB, Recco-Pimentel SM, Cardoso AJ: A second case of multivalent meiotic configurations in diploid species of Anura. Genet Mol Biol 2000, 23:131-133.

36. Siqueira S, Ananias F, Recco-Pimentel SM: Cytogenetics of three Brazilian species of Eleutherodactylus (Anura, Leptodactylidae) with 22 chromosomes and re-analysis of multiple translocations in E. binotatus. Genet Mol Biol 2004, 27:363-372.

37. Carvalho KA, Garcia PC, Recco-Pimentel SM: NOR dispersion, telomeric sequence detection in centromeric regions and meiotic multivalent configurations in species of the Aplastodiscus albofrenatus group (Anura, Hylidae). Cytogenet Genome Res 2009, 126:359-367.

38. Grützner F, Rens W, Tsend-Ayush E, El-Moghharbel N, O'Brien PCM, Jones RC, Ferguson-Smith MA, Graves JAM: In the platypus a meiotic chain of ten sex chromosomes shares genes with the bird $\mathrm{Z}$ and mammal $\mathrm{X}$ chromosomes. Nature 2004, 3021:1-5.

39. Heyer WR, Diment MJ: The karyotype of Vanzolinius discodactylus and comments on usefulness of karyotypes in determining relationships in the Leptodactylus complex (Amphibia, Leptodactylidae). Proc Biol SOC Washington 1974, 87:327-336.

40. Meyne J, Baker RJ, Hobart HH, Hsu TC, Ryder OA, Ward OG, Wiley JE, Wurster-Hill DH, Yates TL, Moyzis RK: Distribution of non-telomeric sites of the $(T \mathrm{AGGG})_{\mathrm{n}}$ telomeric sequence in vertebrate chromosomes. Chromosoma 1990, 99:3-10.

41. Wiley JE, Meyne J, Little ML, Storet JC: Intersticial hybridization sites of the (TTAGGG) telomeric sequence on the chromosomes of some North American hylid frogs. Cytogenet Cell Genet 1992, 61:55-57.

42. Nanda I, Fugate M, Steinlein C, Schmid M: Distribution of (TTAGGG) telomeric sequences in karyotypes of the Xenopus species complex. Cytogenet Genome Res 2008, 122:396-400.

43. Gruber SL, Zina J, Narimatsu H, Haddad CFB, Kasahara S: Comparative karyotype analysis and chromosome evolution in the genus Aplastodiscus (Cophomantini, Hylinae, Hylidae). BMC Genet 2012, 13:28

44. Ventura K, Silva MJJ, Fagundes V, Yonenaga-Yassuda Y: Non-telomeric sites as evidence of chromosomal rearrangement and repetitive (TTAGGG) arrays in heterochromatic and euchromatic regions in four species of Akodon (Rodentia, Muridae). Cytogenet Genome Res 2006, 115:169-175.

45. Martins C, Cabral-de-Mello DC, Valente GT, Mazzuchelli J, Oliveira SG: Cytogenetic mapping and contribution to the knowledge of animal genomes. In Advances in Genetics Research. Volume 4. Edited by Urbano KV. Hauppauge: Nova Science Publishers; 2011:1-82.

doi:10.1186/1471-2156-13-109

Cite this article as: Gazoni et al:: Cytogenetic analyses of eight species in the genus Leptodactylus Fitzinger, 1843 (Amphibia, Anura,

Leptodactylidae), including a new diploid number and a karyotype with multiple translocations. BMC Genetics 2012 13:109.

\section{Submit your next manuscript to BioMed Central and take full advantage of:}

- Convenient online submission

- Thorough peer review

- No space constraints or color figure charges

- Immediate publication on acceptance

- Inclusion in PubMed, CAS, Scopus and Google Scholar

- Research which is freely available for redistribution

Submit your manuscript at www.biomedcentral.com/submit
C Biomed Central 